\title{
EXPERIMENTAL CHARACTERIZATION OF A PHOTO-ACOUSTIC MEASUREMENT SYSTEM
}

\author{
UDC 535.3/.4
}

\author{
Slobodan Todosijević ${ }^{1,2}$, Dejan Ćirić3 ${ }^{3}$, Branko Radičević2 \\ Zlatan Šoškić ${ }^{2}$ \\ ${ }^{1}$ University of Belgrade, School of Electrical Engineering, Serbia \\ ${ }^{2}$ University of Kragujevac, Faculty of Mechanical and Civil Engineering in Kraljevo, Serbia \\ ${ }^{3}$ University of Niš, Faculty of Electronic Engineering, Nišs, Serbia
}

\begin{abstract}
The photoacoustic effect, as a non-destructive method, has increased application in defining thermal and optical properties of materials. Since the measurement of photoacoustic signal requires use of an electronic system, knowledge of the transfer function of the measurement system is a prerequisite for its application. This paper presents two different experimental techniques for the determination of the transfer function of a PA measurement system.
\end{abstract}

Key words: Photoacoustic experimental system, transfer function

\section{INTRODUCTION}

The PA effect is the generation of sound waves in a sample and its surroundings due to the exposure to modulated optical radiation [1]. The effect was discovered and reported by A.G. Bell at the end of the 19th century, but the proper explanation was given almost one hundred years later [1]. The explanation and further theoretical studies were based on the classical heat propagation theory, and they boosted experimental research and practical applications [2] of the PA effect.

A conceptual diagram of the PA measurement system is presented in Fig. 1. The light source emits light under control of the modulator. The modulated light beam irradiates the sample that absorbs a part of the light, and a part of the absorbed light is converted into heat.

Received March 31, 2017 / Accepted June 1, 2017

Corresponding author: Slobodan Todosijević

University of Belgrade, School of Electrical Engineering, 73 Bulevar kralja Aleksandra ,11000 Belgrade, Serbia

E-mail: todosijevic.s@mfkv.rs 


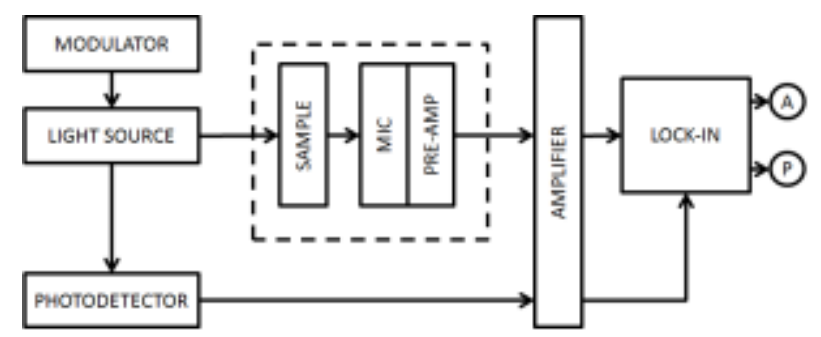

Fig. 1 Photoacoustic measurement setup

Heat transfer through the sample causes deformation of the sample and heat transfer to the surroundings causes expansion of the thin layer of the surrounding medium. Both the deformation of the sample and the expansion of the surrounding medium cause sound emission. The emitted sound waves propagate through a closed space of a PA cell and are detected by a microphone [3-4]. The majority of microphones used in the PA experiments are audio microphones with the frequency range from $20 \mathrm{~Hz}$ to $20 \mathrm{kHz}$. The signal of the microphone transducer is conditioned by the pre-amplifier of the microphone and led by a cable to an amplifier. The amplified microphone signal is led to one input of the lock-in detector. The amplified signal of the photo detector that is illuminated by the same optical beam as the sample is led to the other input of the lock-in detector. The output of the lock-in detector consists of two signals: 1) the ratio between the amplitudes of the signals of the microphone and the photo-detector A, and 2) the phase difference between the signals $P$ [4].

In the described measurement system, excitation and detection parts can be separated. In this case the excitation part consists of the light source, the modulator and the sample, while the detection part consists of the photo detector, the microphone, the amplifier and the lock-in detector. The excitation part has the variable light intensity $I(f)$ as the input, and the acoustic pressure $p_{P A}(f)$ which represents the PA response, as the output. The detection system has the acoustic pressure as the input, and if the two outputs of the lockin detector at modulation frequency $f, A(f)$ and $P(f)$ are considered in the form $\underline{Y}(s=i 2 \pi f)=$ $A(f) \cdot \exp (i 2 \pi f P)$, the Laplace transform of the output of the detection part and the complete PA measurement system may be represented as

$$
\underline{Y}(s)=\underline{p}_{P A}(s) \underline{G}(s)
$$

where $\underline{p}_{P A}(s)$ stands for the Laplace transform of PA response and $\underline{G}(s)$ stands for the transfer function of the detection part of the PA measurement system. If $\underline{G}(s)$ is known, then the amplitude $p_{P A}(f)$ and the phase $\varphi_{P A}(f)$ of the PA response may be extracted from the PA measurement data as

$$
\begin{array}{r}
\underline{p}_{P A}(s)=\frac{\underline{Y}(s)}{\underline{G}(s)} \Rightarrow p_{P A}(f)=\frac{A(f)}{|\underline{G}(i 2 \pi f)|} \\
\varphi_{P A}(f)=P(f)-\arg \underline{G}(i 2 \pi f)
\end{array}
$$

Since the optical processes in the excitation part of the PA measurement system are much faster than the processes in the detection system, the transfer function of the complete PA measurement system (which has the modulated light as input and the 
outputs of the lock-in detector $A(f)$ and $P(f)$ as the output), may be considered to be proportional to $G(s)$. The transfer function of the PA measurement system may be determined using various techniques. The experimental characterization of a measurement system, also known as the calibration of the measurement system, comprises measurement of the output of a system that is exposed to a known input. Various calibration methods use different types of input signals. Acoustic systems are usually calibrated by harmonic input and white noise input.

The analysis given in the paper presents two different techniques for calibration of the PA system that is being developed at the Faculty of Mechanical and Civil Engineering in Kraljevo. The results obtained by the two techniques are compared, and the conclusion on their applicability and further directions of research are derived.

\section{EXPERIMENT}

Due to the small amplitudes of the PA generated sound, the distance between the sample and the microphone should be as small as possible. Microphones with small dimensions are the most suitable for the purpose, and in this research small commercial microphones manufactured by the company Kingstate Electronics Corp are studied, two KEEG1538WB-100LB microphones with $4 \mathrm{~mm}$ diameter (Fig. 2a) and one KECG2742TBL-A microphone with $6 \mathrm{~mm}$ diameter (Fig. 2b). The manufacturer declares the same frequency response for both types of microphones (Fig 2c.), which is flat in the range $20 \mathrm{~Hz}-7 \mathrm{kHz}$. The power supply for the microphones is provided by a $9 \mathrm{~V}$ battery and a LM78L voltage regulator, as presented by the section designated with dashed lines in Fig. 5.

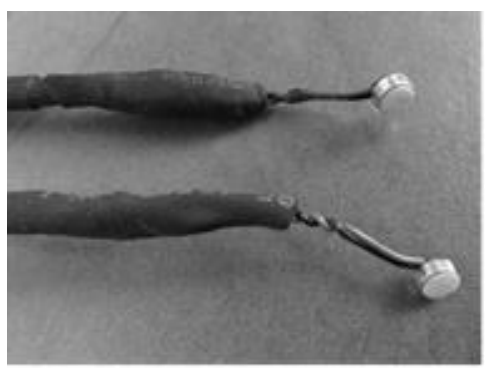

a)

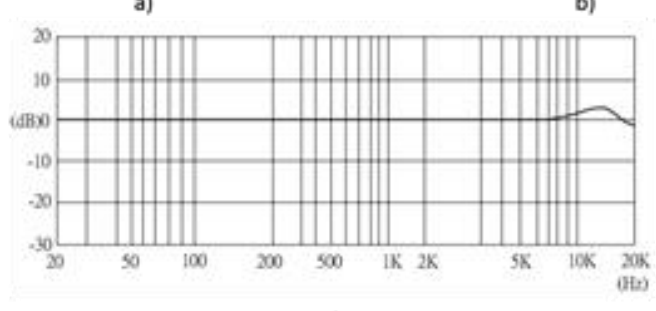

c)

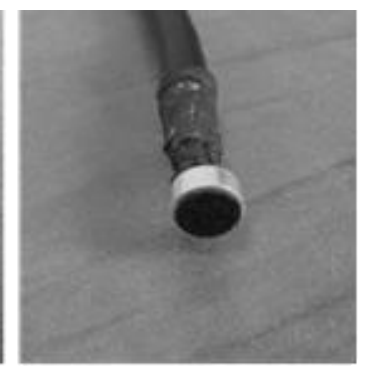

b)

Fig. 2 The microphones with $4 \mathrm{~mm}$ (a) and $6 \mathrm{~mm}$

(b) diameters and c) their frequency response 
The response of the PA measurement system was measured in the anechoic room of Faculty of Electronic Engineering, University of Niš, located in Svrljig. The excitation used for the calibration of the PA measurement was simultaneously measured using the reference acoustic measurement system that consists of the microphone B\&K 4188-A021 and the data acquisition system B\&K 3560-B driven by the Time data recorder application of the Pulse software package. The aim of the measurement of the excitation signal is to take into account the influence of the frequency response of the sound sources that converted electric excitation signal into acoustic excitation. The same excitation setup and the same positions of the microphones were used in all measurements (Fig. 3).

The frequency response of the B\&K 4188-A-021, shown in Fig. 4, is flat in the range $10 \mathrm{~Hz}-10 \mathrm{kHz}$. However, the data acquisition system B\&K 3560-B has the built-in high-frequency filter with cut-off frequency $22.4 \mathrm{~Hz}$ that reduced the passband of the reference measurement system. The sampling rate was set to be $65536 \mathrm{~Hz}$, as it is the highest sampling rate supported by the Time data recorder application. The driver application stores data in the PTI format, but has built-in capability to convert the output data into MAT format used by the data processing software package Matlab.

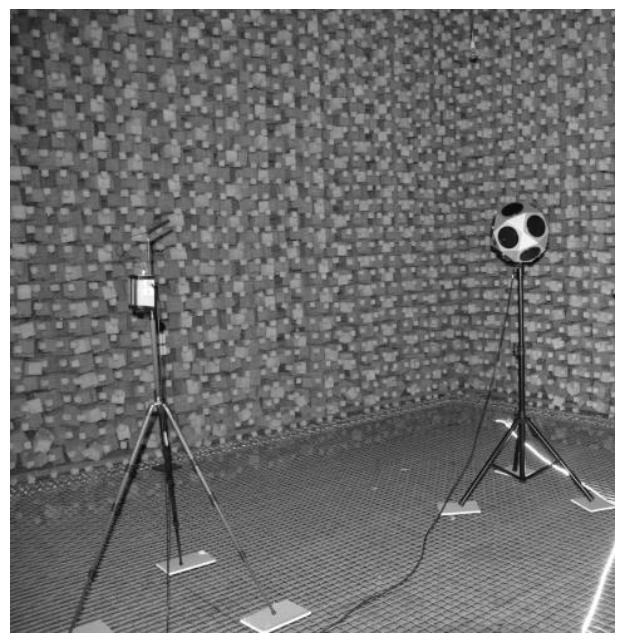

Fig. 3 The sound source and the PA measurement system at the anechoic room during the experiment

Two types of the excitation were used, resulting in two methodologies for characterization of the PA measurement system.

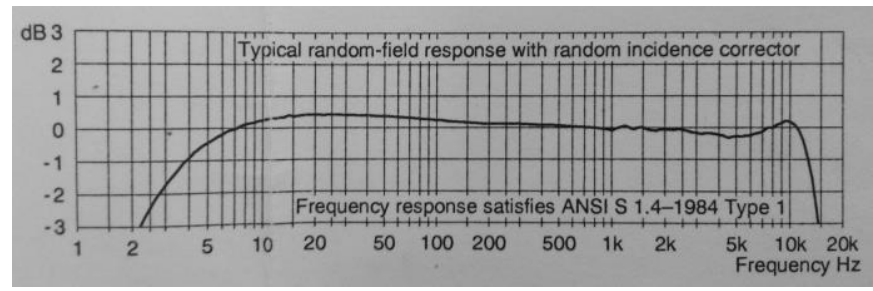

Fig. 4 Frequency response of microphone of the reference measurement system 


\subsection{Excitation by white noise}

In theory, white noise is a random signal that has a frequency characteristic with constant amplitude, $\left|X_{W N}(f)\right|=C$, and random phase over all frequencies. Consequently, the amplitude spectrum of the output of a measurement system excited by white noise signal, $\left|Y_{W N}(f)\right|$, is proportional to amplitude of the transfer function of the measurement system, $|G(f)|$, since

$$
\left|Y_{W N}(s)\right|=|G(s)|\left|X_{W N}(s)\right|=C \cdot|G(s)|
$$

Therefore, the white noise signal is suitable excitation signal for experimental determination of the amplitude of transfer function of measurement systems.

The white noise signal is generated using B\&K Power Amplifier Type 2734 with embedded white noise signal generator, whose output was led to B\&K Omnipower Sound Source Type 4296. According to the manufacturer specification, the white noise signal generated by the power amplifier has the flat amplitude of frequency characteristic in the frequency range $50 \mathrm{~Hz}-5 \mathrm{kHz}$.

The output of the microphones was recorded using M-Audio Fast Track Pro USB digital sound card with the internal amplifier. The 24-bit resolution and $88200 \mathrm{~Hz}$ sampling rate were selected. The measurement was carried out using the Adobe Audition software package and the results were stored in WAV format.

For each of the microphones, seven measurement sessions were performed, each with duration of $16 \mathrm{~s}$. The amplitude spectra of the microphone output signals, as well as the amplitude spectra of the outputs of the reference measurement system, recorded during the all seven sessions, were averaged. Finally, the amplitude spectra of the output of the reference measurement system (in $\mathrm{dBs}$ ) were subtracted from the amplitude spectra of the microphone outputs (also in $\mathrm{dBs}$ ), and the obtained result represents the transfer function amplitude of the PA measurement system.

\subsection{Excitation by sweep signal}

The sweep signal is the signal with constant amplitude and frequency that uniformly increases (sweeps) during the time [5]. In many practical applications, such as echolocation systems, sweep signals are used instead of impulses. With that inspiration, the idea presented in this paper is to use the sweep signal to determine the impulse response of the PA measurement system. If the spectrum of a measured system response to the sweep signal is $Y_{S}(f)$, then the impulse response of the measured system in frequency domain, $H(f)$ as well as in the time domain $h(t)$ may be determined using an appropriate digital filter function with frequency response $F(f)$ called the inverse filter and subsequent convolution [6]:

$$
\begin{aligned}
& H(f)=F(f) \cdot Y_{S}(f) \\
& h(t)=\operatorname{real}\{i F F T[H(f)]\}
\end{aligned}
$$

The transfer function of the PA measurement system is Laplace transform of the impulse response $G(s)=L[h(t)]$.

The sweep signal amplified by a commercial Sony TA-FE510R amplifier was radiated using the omnidirectional dodecahedron-shaped sound source of the Laboratory 
for Acoustics of the Faculty of Electronic Engineering, University of Niš. The exponential sweep signal with frequency range $20 \mathrm{~Hz}-22050 \mathrm{~Hz}$ was recorded in digital WAV format as a file onto a computer. The excitation was reproduced using the 16-bit D/A card NI USB 6351 with sampling frequency $65536 \mathrm{~Hz}$.

The amplifier of the PA measurement system is made using OP07 CP operational amplifier, as presented in Fig. 5. Using the resistor series, the gain of the amplifier may be selected to be $2,4.9,7.8,11,19,48,70$ and 101. The bandwidth-gain product of the amplifier may be estimated to be close to the bandwidth-gain product of the OP07 CP operational amplifier, which is close to $0.5 \mathrm{MHz}$.

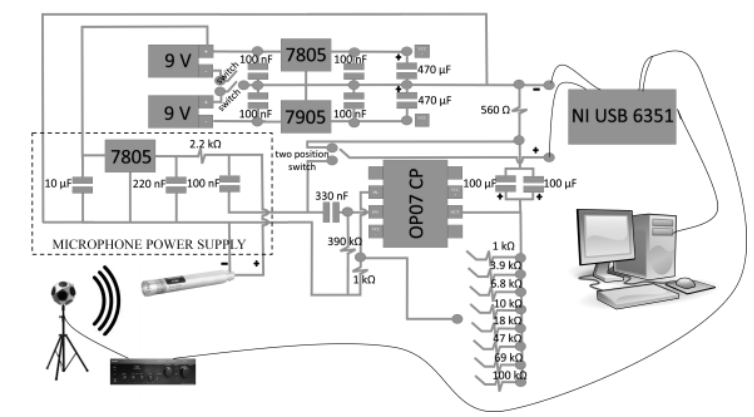

Fig. 5 Experimental setup for measurement of the microphone impulse response

The output of the amplifier is led to the NI USB 6351 data acquisition card that enables 16-bit A/D conversion.

For each of the microphones, five measurement sessions were performed, each with duration of $16 \mathrm{~s}$, as in case of white noise excitation. The amplitude spectra of the microphone output signals as well as the amplitude spectra of the outputs of the reference measurement system recorded during all five sessions were averaged. Finally, the amplitude spectra of the output of the reference measurement system (in $\mathrm{dBs}$ ) were subtracted from the amplitude spectra of the microphone output (also in $\mathrm{dBs}$ ), and the obtained result represents the transfer function amplitude of the PA measurement system.

\section{RESULTS AND DISCUSION}

The transfer functions of the three studied PA measurement systems with different microphones are presented in Fig. 6.

The transfer function amplitude in the frequency range $50 \mathrm{~Hz}-5 \mathrm{kHz}$ determined using the white noise shows variation about $\pm 10 \mathrm{~dB}$ in the range $2-3 \mathrm{kHz}$, and about $\pm 20 \mathrm{~dB}$ close to $3 \mathrm{kHz}$, see Fig. $6 \mathrm{a}$.

When the sweep signal was used to determine the transfer function in the frequency range $20 \mathrm{~Hz}-22050 \mathrm{~Hz}$, the variations about $\pm 5 \mathrm{~dB}$ appear in the range $2-2.6 \mathrm{kHz}$, with several approximately equidistant peaks with $50 \mathrm{~Hz}$ difference. However, the large variations at the frequency of $3 \mathrm{kHz}$ are not observed indicating that the feature may be an artifact of the experimental setup with white noise excitation and not an intrinsic characteristic of the PA measurement system. If the variations in the frequency range from 2 to $2.6 \mathrm{kHz}$ are also considered to be an artifact of the experimental setup with 
sweep excitation because they do not appear in the transfer function obtained by the white noise excitation, then the transfer function of the studied PA system may be considered flat (with variations less than $\pm 3 \mathrm{~dB}$ ) in the frequency range $20 \mathrm{~Hz}-6 \mathrm{kHz}$.

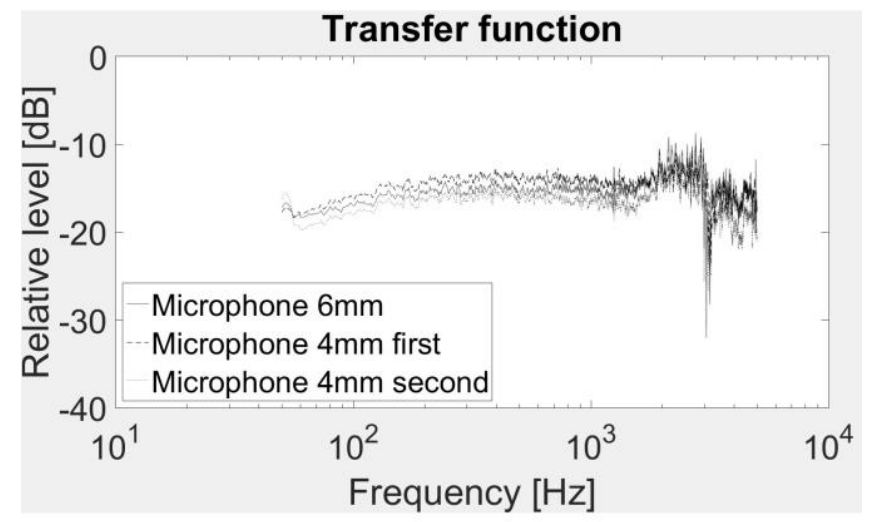

a)

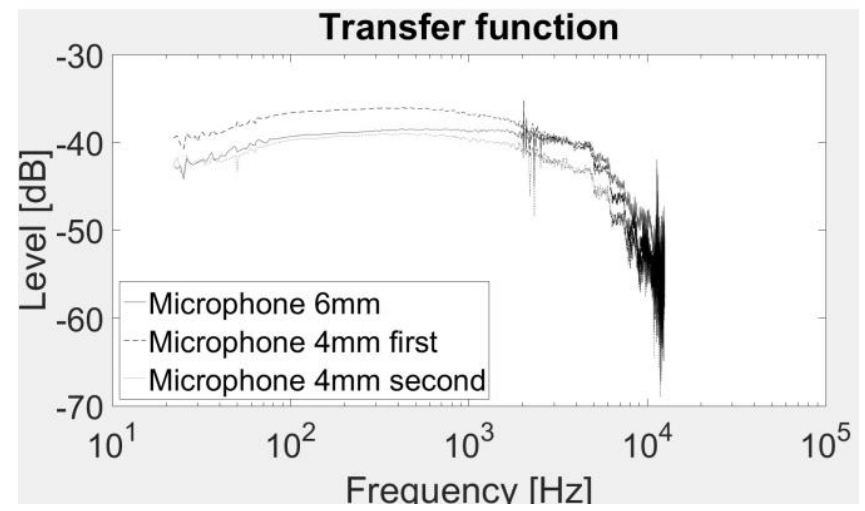

Fig. 6 The amplitude of the transfer function of the studied PA measurement systems using excitation by a) the white noise and b) the sweep signal

Since the gain of the amplifier used in the experimental setup for characterization by the sweep signal was set to be 70, it can be estimated that the cut-off frequency of the amplifier was around $6 \mathrm{kHz}$, which probably explains the drop in the amplitude of the transfer function of the PA measurement systems observed at frequencies higher than 6 $\mathrm{kHz}$, which may be observed in Fig. $6 \mathrm{~b}$.

\section{CONCLUSION}

The paper presented the characterization of three PA measurement systems with the same concept and difference in the microphone only. Two methodologies for experimental determination of the transfer function of the PA system were used, the first based on excitation by the white noise and the second based on excitation by the sweep signal. 
The results have shown that the obtained results differ at high frequencies, and there is an indication that each of the methodologies introduces its own artifacts into the obtained transfer function of the PA measurement system. Therefore, the application of both methodologies in the process of determination of the PA system transfer characteristic seems to be the most reliable approach.

The described process of development of the methodologies for calibration of the PA measurement systems shows that many variations in the experimental setups were made: sound sources, amplifiers and data acquisition systems used to implement the two methodologies were different. These variations represent the additional sources of unreliability. The presented study can be used for comparison of different measurements approaches. Further research should focus on the uniform solution and techniques in order to open the possibilities to compare the methodologies in a controlled manner, and to define the procedure for calibration of the PA measurement systems in a better way.

Acknowledgement: The paper presents a part of the research performed within the framework of the project of Technological Development Program of Republic of Serbia "Development of methodologies and means for protection of urban areas from noise pollution" no. TR37020. The authors would like to thank the Ministry of Education and Science of the Republic of Serbia for supporting this research.

\section{REFERENCES}

1. A. Rosencwaig, Photoacoustics and Photoacoustic Spectroscopy (R. E. Krieger Publishing Company, Malabar, Florida, 1980)

2. Andrew C.Tam, "Applications of photoacoustic sensing techniques." Reviews of Modern Physics 58, no. 2 (1986): 381 .

3. Slobodan Todosijević, Slobodanka Galović, Jelena Tomić, Zlatan Šoškić, Developing Model of a Photoacoustic Measurement System, Proceedings of the 8th International Conference Heavy Machinery 2014, Zlatibor, 24-26.06.2014, pp. G 45-50, ISBN 978-86-82631-74-3

4. Mihailo D Rabasovic, Marko G Nikolic, Miroslav D Dramicanin, Mladen Franko and Dragan D Markushev, Low-cost, portable photoacoustic setup for solid samples, Meas. Sci. Technol. 20 (2009) 095902.

5. Steven, W. Smith. "The scientist and engineer's guide to digital signal processing." California Technical Pub (1997)

6. S. Müller, Measuring transfer-functions and impulse responses, in: Finn Jacobsen (Ed), Part I: Acoustic Signals and Systems, in:D. Havelock, S. Kuwano, M. Vorländer (Eds.), Handbook of Signal Processing in Acoustics, Volume 1, Springer Science, New York, 2008, pp. 65-86

\section{EKSPERIMENTALNA KARAKTERIZACIJA FOTOAKUSTIČKOG MERNOG SISTEMA}

Fotoakustički (FA) efekat kao nedestruktivna metoda ima sve veću primenu u određivanju termičkih $i$ optičkih osobina materijala. S obzirom da merenje fotoakustičkog signala zahteva upotrebu elektronskog sistema, poznavanje prenosne funkcije mernog sistema postaje preduslov za njegovu primenu. Ovaj rad predstavlja dve različite eksperimentlane tehnike za određivanje prenosne funkcije FA mernog sistema.

Ključne reči: Fotoakustički merni sistem, funkcija prenosa 